\begin{tabular}{|c|l|}
\hline Title & A dhesion shear theory of ice friction at low sliding vel ocities, combined with ice sintering \\
\hline Author(s) & Maeno, Norikazu; A rakawa, Masahiko \\
\hline Citation & $\begin{array}{l}\text { Journal of A pplied Physics, 95(1), 134.139 } \\
\text { https://doi.org/10.1063/1.1633654 }\end{array}$ \\
\hline Issue Date & 2004 01 \\
\hline Doc URL & http://hdl.handle.net/2115/5869 \\
\hline Rights & Copyright $\odot 2004$ American Institute of Physics \\
\hline Type & article \\
\hline File Information & JAP95-1.pdf \\
\hline
\end{tabular}

Instructions for use 


\title{
Adhesion shear theory of ice friction at low sliding velocities, combined with ice sintering
}

\author{
Norikazu Maeno a) and Masahiko Arakawa \\ Institute of Low Temperature Science, Hokkaido University, N-19 W-8, Kita-ku, Sapporo 060-0819, Japan
}

(Received 1 April 2003; accepted 24 October 2003)

\begin{abstract}
Adhesion and shear deformation of ice have been traditionally considered to be responsible for ice friction at sliding velocities lower than about $10^{-2} \mathrm{~m} / \mathrm{s}$, but the simple mechanism cannot explain the recent finding that the ice-ice friction coefficient increases with decreasing sliding velocity. This article proposes an improved adhesion shear theory, which takes account of junction growth of asperities at the sliding ice interface due to sintering. At lower sliding velocities and higher homologous temperatures, contacts of ice asperities develop resulting in the increase of friction force. (c) 2004 American Institute of Physics. [DOI: 10.1063/1.1633654]
\end{abstract}

\section{INTRODUCTION}

Ice is known as one of the most slippery materials as its friction coefficient often becomes as low as 0.01 or even lower. The low friction property of ice has been studied by many researchers for over hundred years, ${ }^{1-7}$ and now is generally explained by two physical mechanisms which work at two different regions of sliding velocity. One is the water lubrication mechanism working at sliding velocities above roughly $0.01 \mathrm{~m} / \mathrm{s}$ and the other is the adhesion and plastic deformation of ice at the friction interface which works at velocities lower than roughly $0.01 \mathrm{~m} / \mathrm{s}$.

The water lubrication mechanism is characterized by the low viscous resistance of water film produced by frictional heat at the sliding ice interface, which was proposed by Bowden and Hughes. ${ }^{3}$ Later, the physical processes involved were extensively studied by Evans et $a l^{5}$ and then a reasonable quantitative expression for the friction coefficient was formulated by Oksanen and Keinonen ${ }^{8}$ as a function of sliding velocity, temperature, and normal stress. The model of Oksanen and Keinonen explains fairly well the measured result of the complex behavior of ice friction coefficients, that is the decrease $\left(v^{-1 / 2}\right)$ and increase $\left(v^{1 / 2}\right)$ with the increasing sliding velocity, $v$ (Fig. 1). The first decrease of the friction coefficient is attributed to the appearance and development of water film and the subsequent increase is due to the increase of viscous resistance.

On the other hand, the direct measurement of the low friction coefficient of ice at lower velocities than about 0.01 $\mathrm{m} / \mathrm{s}$ is very difficult and the low friction seems rather a speculative conclusion deduced from the fact that the shear strength of ice is generally much smaller compared to other materials. Barnes et al. ${ }^{6}$ and Tusima ${ }^{7}$ performed low velocity friction measurements of ice by sliding a piece of coneshaped ice of included angle $170^{\circ}$ on brass, granite, glass, and steel plates (Barnes et al.), ${ }^{6}$ and a steel ball on an ice plate (Tusima). ${ }^{7}$ Both the authors suggested that the friction coefficient of ice may be small and the friction is attributable to adhesion and plastic deformation of ice. It should be

${ }^{a)}$ Electronic mail: maeno@lowtem.hokudai.ac.jp noted, however, that in their measurements, obtained forces are sometimes dominated by ploughing forces instead of pure friction forces because of the preferential plastic deformation (plough) of ice due to the shape of sliders.

Most previous ice friction measurements have been carried out between ice and other materials with practical applications to skates, skis, and other various structural interactions in ice environments and, in many cases, the surfaces of sliding samples were not flat, which resulted in ploughing or abrasion effects which are usually the main component of measured frictional forces. Moreover, the ice surface is known to be very reactive and its nature may change easily by contact with other materials.

Our systematic study has been initiated aimed at gaining insight into the ice friction mechanism by making ice-ice friction measurements in wide ranges of sliding velocity, temperature, and normal pressure, using flat surfaces of ice. Figure 1 summarizes ice-ice friction coefficients around $-10{ }^{\circ} \mathrm{C}$ reported so far including four reports of our systematic study ${ }^{9-12}$ and other ice-ice friction data. ${ }^{3,8,13-15}$ The result of ice-ice friction coefficients at lower velocities below $0.01 \mathrm{~m} / \mathrm{s}$ is different from what has been expected on the basis of the adhesion and plastic deformation mechanism of ice. The measured result shows that with decreasing sliding velocity from $0.1 \mathrm{~m} / \mathrm{s}$, the ice-ice friction coefficient increases due to the decrease of production of frictional heat to form water film and stick-slip behavior appears around $10^{-3} \mathrm{~m} / \mathrm{s}$, suggesting the alteration of the working physical mechanism from water lubrication to adhesion and plastic deformation.

The stick-slip behavior ceases at sliding velocities lower than about $10^{-5} \mathrm{~m} / \mathrm{s}$ but the ice-ice friction coefficient does not decrease with the decrease of sliding velocity as expected from the known flow law of ice. ${ }^{6}$ Instead it increases steadily to become as high as 1.0 at $10^{-7} \mathrm{~m} / \mathrm{s}$. There seems no reason to expect that ice is also slippery at these low velocities. The purpose of the present article is to clear up the sophisticated situation of ice friction at low sliding velocities, and to give a physical explanation of the measured velocity dependence of ice-ice friction coefficient at the low velocities. 


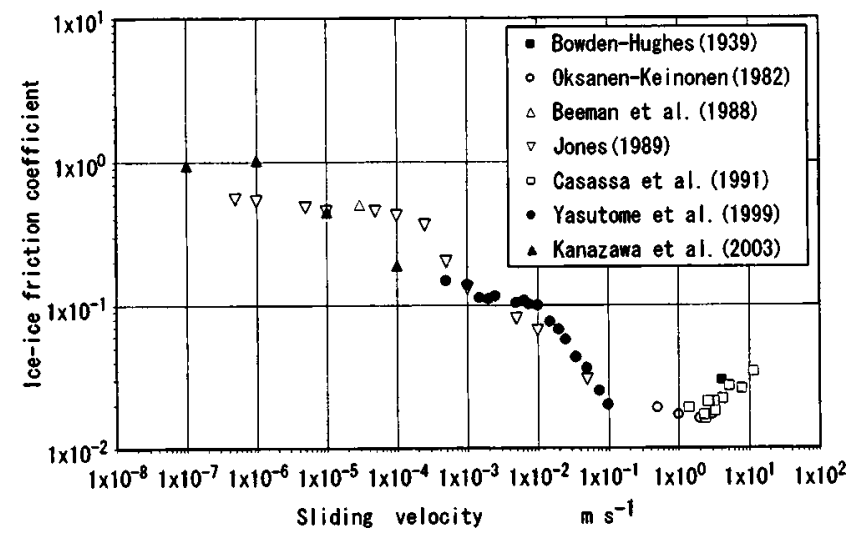

FIG. 1. Summary of ice-ice friction coefficients vs sliding velocity. Most data are obtained around $-10^{\circ} \mathrm{C}$, but those above $0.5 \mathrm{~m} / \mathrm{s}$ are -12 to $-20{ }^{\circ} \mathrm{C}$ and a data point at $-183^{\circ} \mathrm{C}$ is also included. Temperature and normal pressure are: Bowden and Hughes (see Ref. 3) $\left(-12^{\circ} \mathrm{C}\right)$, Oksanen and Keinonen (see Ref. 8) $\left(-15^{\circ} \mathrm{C}, 3.9 \mathrm{kPa}\right)$, Beeman et al. (see Ref. 13) $\left(-183{ }^{\circ} \mathrm{C}, 5 \mathrm{MPa}\right)$, Jones (see Ref. 14$)\left(-10^{\circ} \mathrm{C}, 17.8 \mathrm{kPa}\right)$, Casassa et al. (see Ref. 15) $\left(-20^{\circ} \mathrm{C}, 3.3 \mathrm{kPa}\right)$, Yasutome et al. (see Ref. 9) $\left(-12{ }^{\circ} \mathrm{C}, 6.6\right.$ $\mathrm{kPa})$, and Kanazawa et al. (see Ref. 11) $\left(-10^{\circ} \mathrm{C}, 367.5 \mathrm{kPa}\right)$.

\section{ADHESION SHEAR THEORY OF ICE FRICTION AT LOW SLIDING VELOCITIES}

It is now well accepted that when two ice surfaces are in contact under a normal force $W$, adhesion or real contact is achieved by plastic yielding, and the real contact area $S_{R}$ is given by

$$
S_{R}=W / \sigma,
$$

where $\sigma$ is the compressive yield strength of ice. $S_{R}$ is the sum of contact areas of asperities on the ice surfaces. If the number of contacting asperities is $N$ and the area and radius of each circular asperity contact is $s$ and $r$, respectively,

$$
S_{R}=N s=N \pi r^{2} .
$$

Assuming a random distribution of identical asperities on a solid surface, Lim and Ashby ${ }^{16}$ obtained the following expression for $N$,

$$
N=G f(1-f)+1,
$$

where $G$ is a constant relating to the size of asperities and the nominal (apparent) contact area, $S_{A}$, and $f$ is the ratio of the real and nominal contact areas, that is $S_{R} / S_{A}$,

$$
f=\frac{S_{R}}{S_{A}}=\frac{p_{A}}{\sigma},
$$

where $p_{A}$ is the apparent normal pressure $\left(W / S_{A}\right)$. Equation (3) shows that the number of contacting asperities increases as the normal pressure increases when $f$ is smaller than 0.5 , but it is unity when $f$ is unity. The predictions of Eq. (3) are in good agreement with experimental results of Quinn and Winer ${ }^{17}$ who found that $N$ ranged from 4 to 10 when $f$ ranged from $1.2 \times 10^{-4}$ to $6.6 \times 10^{-4}$. As direct observations of contacting asperities on ice surfaces have never been done due to technical difficulties, we assume the relation is also applicable to ice contact, and we estimate the number density of contacting asperities per unit area of ice surface as $Z$ $=N / S_{A}$ assuming $G=10^{6}$ based on the results of Quinn and Winer. ${ }^{17}$

The adhesion theory of dry friction of metals was extensively developed by Tabor ${ }^{18}$ who considered the junction growth in a combined condition of shear and normal stresses, and by introducing an adhesion parameter $k$ explained the large variation of the friction coefficient from zero to infinity, which corresponds to $k=0$ and $k=1$, respectively. $k$ was defined as

$$
k=\frac{\tau}{\tau_{\text {bulk }}}, \quad 0 \leqslant k \leqslant 1,
$$

where $\tau$ and $\tau_{\text {bulk }}$ are the critical shear stresses or strengths of the interfacial layer and the bulk, respectively. The theory suggests that on perfectly clean interfaces, junction growth goes on indefinitely and friction or sliding does not occur.

In our adhesion shear theory of ice friction at low sliding velocities, we take account of the junction growth due to thermal sintering which produces the larger frictional shear at the lower velocities. The thermal sintering is usually unimportant in ordinary metals and other materials at normal temperatures, but it is essentially important in the case of ice because of its extremely high homologous temperature. As the melting point of ice is $0^{\circ} \mathrm{C}$ at normal pressures, the homologous temperature of usual experiments of ice, e.g., -10 to $-30{ }^{\circ} \mathrm{C}$, is 0.96 to 0.89 , and sintering takes place extremely rapidly resulting in the increase of the junction or real contact area.

When two ice surfaces are in contact and slide against each other, a fractional number of asperities on both the surfaces collide, adhere, slide (sheared plastically), and then detach. We assume that the contact area of each asperity increases by $\Delta s$ during the contact time $\Delta t$. In the ice-ice friction without ploughing, the friction force $F$ originates only from the shear stress required to deform the interfacial thin ice layer on the sliding surfaces. By assuming that the frictional shear stress is the sum of stresses exerted to $N$ contacting asperities, the friction coefficient $\mu$ is written as

$$
\mu=\frac{F}{W}=\frac{N(s+\Delta s) \tau}{N s \sigma}=\left(1+\frac{\Delta s}{s}\right) \frac{\tau}{\sigma} .
$$

Equation (6) implies that the ice friction coefficient increases when the contact area increases by sintering. The increase can become significant at lower sliding velocities and higher temperatures.

\section{JUNCTION GROWTH DUE TO THERMAL SINTERING}

Ice sintering has been investigated conventionally by observing growth rates of junctions formed between two ice spheres in contact. ${ }^{19-23}$ All of the authors found the following relation among the junction radius, $r$, ice sphere radius, $R$, and time, $t$,

$$
\left(\frac{r}{R}\right)^{q}=\frac{C}{R^{p}} t,
$$




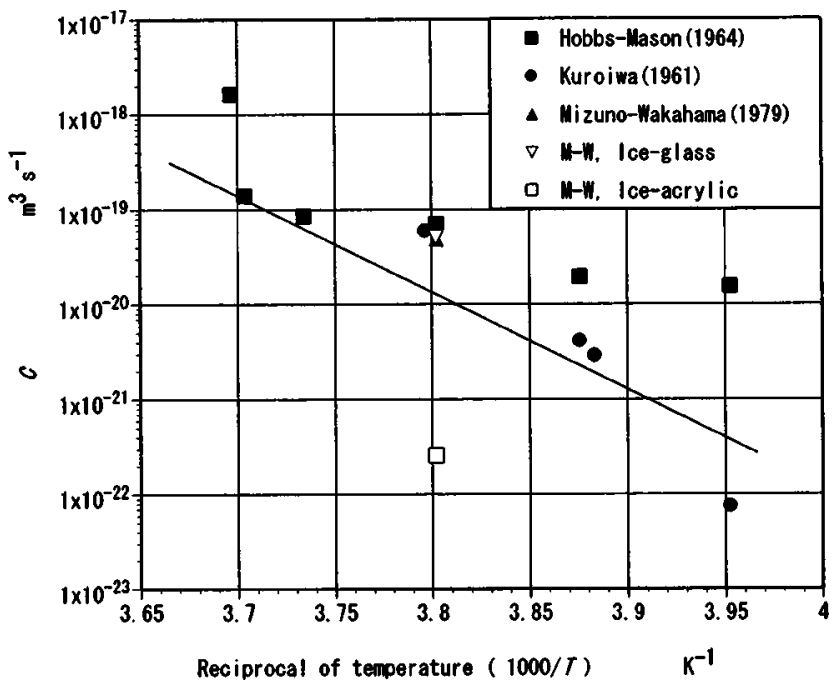

FIG. 2. Temperature parameter $C$ for the ice sintering process versus the reciprocal of temperature. The regression line is Eq. (8). Values of $C$ for ice-glass and ice-acrylic sintering are also included.

where $C$ is a constant depending on temperature, and $p$ and $q$ are numerical constants specified by each working physical mechanism. By comparing the measured values of $p$ and $q$ with those predicted by theories developed by Kuczynski ${ }^{24}$ and others, the above authors tried to find a dominant mechanism working in ice sintering, but their obtained values were all different, $p$ ranging from 2.8 to 4.0 and $q$ from 4.0 to 7.7 , and consequently led to different confusing conclusions. Maeno and Ebinuma ${ }^{25}$ explained that the ice sintering is not realized by a single mechanism at the usual experimental temperatures due to high homologous temperatures, but that several, at least six, physical mechanisms work together in ice sintering.

However, we can obtain an empirical expression for junction growth due to ice sintering by reanalyzing their data. We used numerical data reported by Kuroiwa, ${ }^{20}$ Hobbs and Mason, ${ }^{21}$ and Mizuno and Wakahama ${ }^{26}$ since all of their data showed the radius dependence of $p=3$ and the plot of the quantity $(r / R)^{q} R^{3}$ against time showed a fairly good linear relation at each radius and temperature. Figure 2 gives the constant $C$ thus estimated plotted against the reciprocal of absolute temperature. The data points can well be expressed, as follows, taking account of errors involved in their measurements,

$$
C=C_{0} \exp \left(-\frac{E_{s}}{R_{G} T}\right),
$$

where $R_{G}$ and $T$ are the gas constant and absolute temperature, respectively, and the two constants are $C_{0}$ $=4.14 \times 10^{19} \mathrm{~m}^{3} / \mathrm{s}$ and $E_{s}=196.5 \mathrm{~kJ} / \mathrm{mol}$. It is clear in Fig. 2 that $C$ of ice sintering to an acrylic plate is much smaller than that estimated from Eq. (8).

When the radius of the initial circular contact is $r$ and it increases to $r+\Delta r$ in a contact time $\Delta t$, then from Eq. (7) we have the following relation,

$$
\left(1+\frac{\Delta r}{r}\right)^{q}=1+\frac{C R^{q-p}}{r^{q}} \Delta t .
$$

\section{SLIDING VELOCITY DEPENDENCE OF ICE-ICE FRICTION COEFFICIENT}

From Eqs. (6) and (9), the ice-ice friction coefficient can be written as follows:

$$
\mu=\left(1+\frac{\Delta s}{s}\right) \frac{\tau}{\sigma}=\left(1+\frac{\Delta r}{r}\right)^{2} \frac{\tau}{\sigma}=L \frac{\tau}{\sigma},
$$

where $L$ is defined as

$$
L=\left[1+2 C\left(\frac{r}{R}\right)^{1-q} \frac{R^{1-p}}{v}\right]^{2 / q} .
$$

Here, the ice sphere radius $R$ was put equal to that of an asperity and $\Delta t$ was put as $2 r / v$ where $v$ is the sliding velocity. Hereafter, we call $L$ the sintering factor for ice friction.

To calculate $\mu$ we need $\tau$ and $\sigma$ as functions of sliding velocity and temperature. For the interfacial shear strength $\tau=k \tau_{\text {bulk }}$, we adopt the experimental data of Barnes et al., ${ }^{6}$ which give the two alternatives:

$$
\dot{\varepsilon}_{\tau}=A \tau_{\text {bulk }}^{n} \exp \left(-\frac{E_{\tau}}{R_{G} T}\right),
$$

or

$$
\dot{\varepsilon}_{\tau}=A\left(\sinh \alpha \tau_{\text {bulk }}\right)^{n} \exp \left(-\frac{E_{\tau}}{R_{G} T}\right),
$$

where $\dot{\varepsilon}_{\tau}$ is the shear strain rate, $A$ and $n$ are numerical constants, and $E_{\tau}$ is the activation energy for creep. The numerical constants are as follows when $\dot{\varepsilon}_{\tau}$ and $\tau_{\text {bulk }}$ are measured in $\mathrm{s}^{-1}$ and $\mathrm{MPa}$, respectively. Equation (12): $A$ $=6.5 \times 10^{8} \mathrm{~s}^{-1} \mathrm{MPa}^{-n}, n=3.01$, and $E_{\tau}=78.6 \mathrm{~kJ} / \mathrm{mol}$ in a temperature range from -8 to $-14{ }^{\circ} \mathrm{C}$, and Eq. (13): $A$ $=2.72 \times 10^{10} \mathrm{~s}^{-1}, \quad \alpha=0.262 \mathrm{MPa}^{-1}, \quad n=3.05, \quad$ and $E_{\tau}$ $=78.1 \mathrm{~kJ} / \mathrm{mol}$ in a temperature range from -8 to $-45^{\circ} \mathrm{C}$. Equation (13) holds in a wider range of stress and temperature and reduces to the Arrhenius-type equation, Eq. (12), when $\alpha \tau \leqslant 0.8$. We further assume that the shear strain rate is expressed by $\dot{\varepsilon}_{\tau}=v / \delta$, where $\delta$ is the thickness of the interfacial layer of ice at the contact. In the calculation, $\delta$ was put as $1 \times 10^{-4} \mathrm{~m}$ from microscopic observations of the ice surfaces after the friction experiments.

For the compressive yield stress, $\sigma$, we must use the maximum compressive strength of ice at various strain rates in an unconfined condition since we are dealing with the compressive yield process of ice asperities without ploughing. As those experimental values of $\sigma$, we find published results by Jones ${ }^{27}$ at $-11^{\circ} \mathrm{C}, \mathrm{Cole}^{28}$ at $-5^{\circ} \mathrm{C}$, and Arakawa and Maeno ${ }^{29}$ at -10 to $-173{ }^{\circ} \mathrm{C}$. We adopt Arakawa and Maeno's data ${ }^{29}$ of unconfined uniaxial compressive measurement. Their result of ductile deformation was summarized in the following empirical equation:

$$
\dot{\varepsilon}_{\sigma}=A_{\sigma} \sigma^{m} \exp \left(-\frac{E_{\sigma}}{R_{G} T}\right),
$$

where $\dot{\varepsilon}_{\sigma}$ is the compressive strain rate in $\mathrm{s}^{-1}, \sigma$ is the maximum stress in $\mathrm{MPa}$, and the numerical constants are $A_{\sigma}$ $=2.731 \times 10^{6} \mathrm{~s}^{-1} \mathrm{MPa}^{-m}, m=3.4$, and $E_{\sigma}=63.8 \mathrm{~kJ} / \mathrm{mol}$. Effective ranges of temperature and strain rate in which duc- 


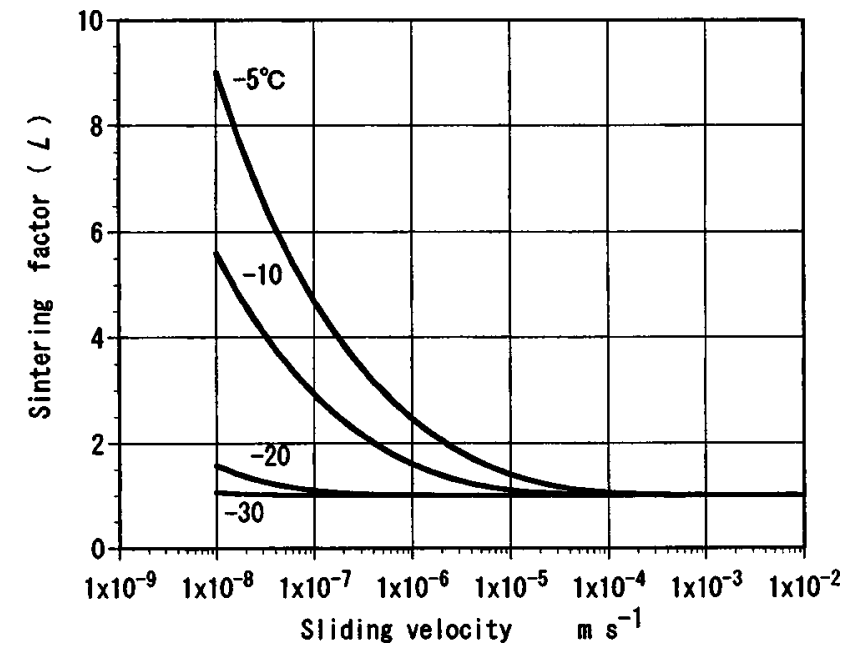

FIG. 3. Sintering factor $L$ vs sliding velocity at different temperatures. $S_{A}$ $=4 \times 10^{-4} \mathrm{~m}^{2}, p_{A}=10 \mathrm{kPa}, p=3, q=7$, and $R=10^{-4} \mathrm{~m}$.

tile deformation was observed are -10 to $-70{ }^{\circ} \mathrm{C}$ and 4 $\times 10^{-6}$ to $4.2 \times 10^{-4} \mathrm{~s}^{-1}$ respectively. The strain rate corresponds to the compression velocity of $1.6 \times 10^{-7}$ to 1.7 $\times 10^{-5} \mathrm{~m} / \mathrm{s}$ since the length of their ice sample was $40 \mathrm{~mm}$.

Figure 3 shows the calculated effect of sintering on ice friction, in which the sintering factor $L$ is plotted as a function of sliding velocity and temperature. In the calculation, parameters were put as follows: $S_{A}=4 \times 10^{-4} \mathrm{~m}^{2}$ (size of specimens used in our experiments), $p_{A}=10 \mathrm{kPa}, p=3, q$ $=7$, and $R=10^{-4} \mathrm{~m}$. It is clear from Fig. 3 that the effect of sintering becomes appreciable above about $-20{ }^{\circ} \mathrm{C}$. The sintering factor calculated for different normal pressures at $-10{ }^{\circ} \mathrm{C}$ is shown in Fig. 4, which leads to the conclusion that the change of normal pressure has no significant effect on the sintering factor.

Figure 5 shows the sliding velocity dependence of $\tau / \sigma$ normalized by the value at $0.01 \mathrm{~m} \mathrm{~s}^{-1}$ calculated by use of Eqs. (12) and (14), dashed line, and Eqs. (13) and (14), solid line. Figure 6 gives similarly normalized ice-ice friction co-

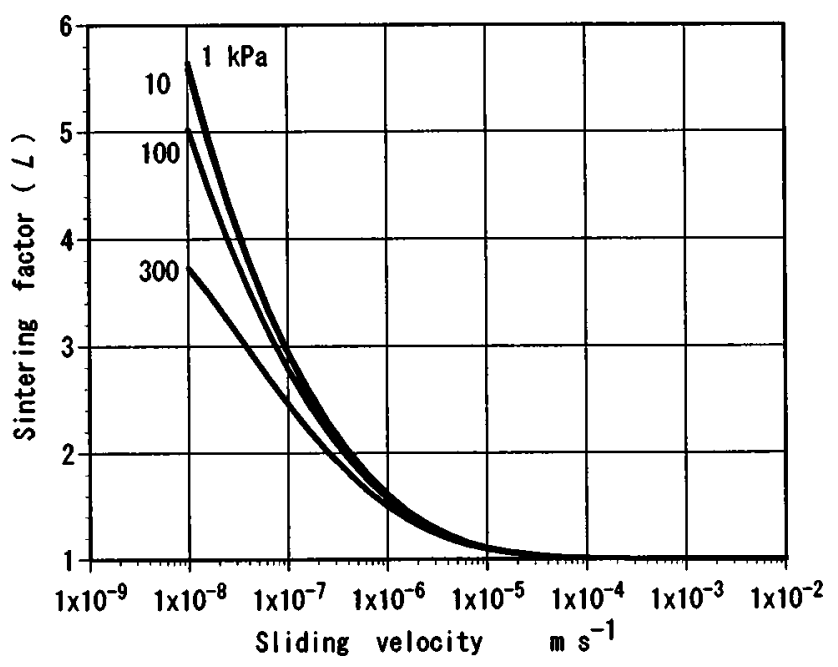

FIG. 4. Sintering factor $L$ vs sliding velocity at different normal pressures $p_{A}$. Temperature $-10^{\circ} \mathrm{C}, p=3, q=7$, and $R=10^{-4} \mathrm{~m}$. The lines of 1 and $10 \mathrm{kPa}$ overlap one another.

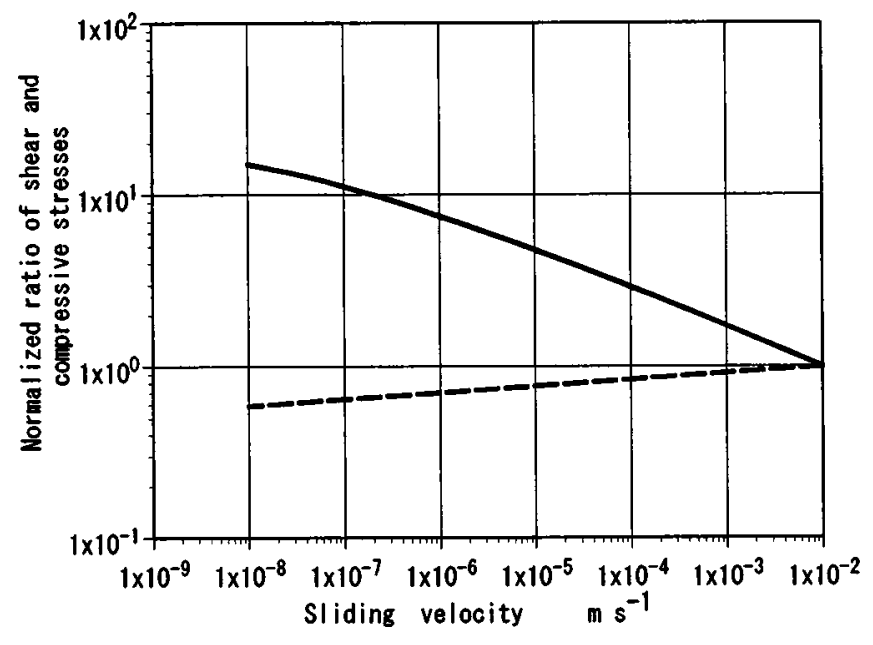

FIG. 5. Ratio of shear and compressive stresses of ice, $\tau / \sigma$, normalized by the value at $0.01 \mathrm{~m} \mathrm{~s}^{-1}$. Temperature is $-10^{\circ} \mathrm{C}$. Solid and dashed lines refer, respectively, to the hyperbolic relation, Eq. (13), and power law, Eq. (12). $p_{A}=10 \mathrm{kPa}$ and $\delta=10^{-4} \mathrm{~m}$.

efficient calculated from Eq. (10). In the calculation, the strain rate in Eqs. (12) and (13) was changed to sliding velocity assuming $\delta=1 \times 10^{-4} \mathrm{~m}$ as described earlier. The strain rate in Eq. (14) was changed to compression velocity using the sample length and assumed equal to the sliding velocity.

The velocity relationship of the dashed line in Fig. 5 is expressed as $v^{1 / n-1 / m}=v^{0.038}$. That is what has been frequently expected in the previous ice friction studies that suggest the ice friction at low velocities might be attributed to adhesion and plastic deformation. ${ }^{6,7}$ However, this is not physically correct because Eq. (12) is only valid for secondary or steady-state creep of ice where the strain rate is smaller than about $10^{-5} \mathrm{~s}^{-1}$, that is the sliding velocity is smaller than about $10^{-9} \mathrm{~m} \mathrm{~s}^{-1}$. The dashed line in Fig. 5 is an imaginary unrealistic result. The same argument applies to the similarly calculated friction coefficient (dashed line) in

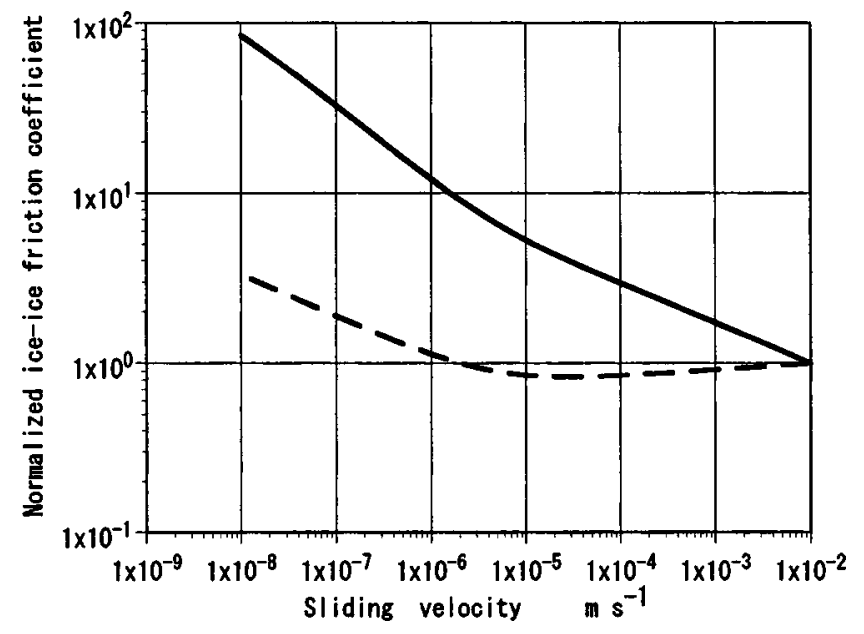

FIG. 6. Ice-ice friction coefficient vs sliding velocity. Values are normalized by the value at $0.01 \mathrm{~m} \mathrm{~s}^{-1}$. Temperature is $-10^{\circ} \mathrm{C}$. $S_{A}=4$ $\times 10^{-4} \mathrm{~m}^{2}, p=3, q=7, p_{A}=10 \mathrm{kPa}, \delta=10^{-4} \mathrm{~m}$, and $R=10^{-4} \mathrm{~m}$. Solid and dashed lines refer, respectively, to the hyperbolic relation, Eq. (13), and power law, Eq. (12). 


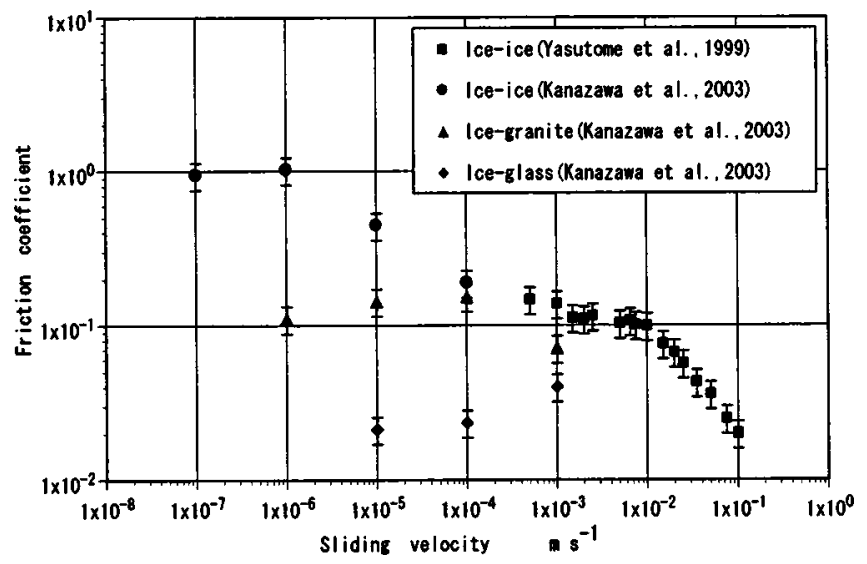

FIG. 7. Ice-ice, ice-granite, and ice-glass friction coefficients vs sliding velocity measured at $-10^{\circ} \mathrm{C}$. Data are from Yasutome et al. (see Ref. 9) and Kanazawa et al. (see Ref. 11).

Fig. 6. The ice-ice friction coefficient calculated by use of Eqs. (10) and (13) shows a marked increase at lower sliding velocities. The trend is in good agreement with the measured results (Fig. 1).

\section{DISCUSSION}

The ice-ice friction at lower sliding velocities below about $0.01 \mathrm{~m} / \mathrm{s}$ is attributed to the adhesion and plastic shear deformation of minute asperities at the sliding ice interface. Our adhesion shear theory could show that with decreasing sliding velocity, the ice-ice friction coefficient increases because the adhered junctions grow by sintering during contact. The effect was quantitatively expressed by the sintering factor, $L$, which becomes significant at lower velocities and higher temperatures. The conclusion is different from that of Kennedy et al. ${ }^{30}$ who recently reanalyzed the data of Jones ${ }^{14}$ at slow sliding velocities as shown in Fig. 1, and attributed the increase to the roughness of sliders. However, their explanation might not be effective to explain the velocity dependence.

The sintering effect is negligibly small at lower temperatures below $-30{ }^{\circ} \mathrm{C}$ (Fig. 3), where we will observe the ice friction behavior caused by the intrinsic plastic property of ice. The increase will not be observed either if sintering does not proceed much because of incomplete adhesion. Figure 7 gives examples of friction coefficients measured for icegranite and ice-glass friction. ${ }^{11}$ We believe that the opposite velocity dependences shown are results of incomplete adhesion between ice and granite or glass.

It was noted in Fig. 5, however, that the power-law-type behavior of the secondary creep of ice cannot be expected in the ice friction, but that the plastic flow of ice should be expressed by the hyperbolic flow law. This implies that the shear deformation of the thin interfacial layer of ice proceeds by the tertiary creep with recrystallization, ${ }^{6}$ but our visual observation of sliding ice surfaces after experiments did not give such evidence. ${ }^{11}$ The observation is supported by the study of Offenbacher et al., ${ }^{31}$ who showed that recrystallization on the sliding ice surface appeared mainly by the result of the normal, not the frictional, force. Thus, this consider- ation leads to the conclusion that the nature of the interfacial layer is different from the bulk, which is discussed below.

The calculation of absolute values of the ice-ice friction coefficient by Eq. (10) requires knowledge of the adhesion factor, $k$. The meaning of $k$ is related to what extent the critical shear strength of the interfacial layer is smaller than that of the bulk ice. As friction takes place, only when the former is smaller than the latter, $k$ is smaller than unity and depends on the fractional contact area, $f$, and the nature of the interfacial layer of ice which is influenced by contamination, reaction with other materials, and so on. In that sense, Jellinek's finding ${ }^{32,33}$ seems very significant that the adhesive tensile strength between ice and stainless steel or fused quartz is at least 15 times larger than adhesive shear strength, and that the shear strength is much smaller than the cohesive strength of the bulk ice. The result was reasonably explained by assuming the presence of quasi-liquid layer at the icesolid interface. He reports that the adhesive shear strength at $-4.5^{\circ} \mathrm{C}$ is $1.0 \mathrm{MPa}$ (ice-steel) and $0.2 \mathrm{MPa}$ (ice-quartz) at the sliding velocity $6 \times 10^{-5} \mathrm{~m} \mathrm{~s}^{-1}$, and it is $16.0 \mathrm{MPa}$ in the case of cohesive break where the break took place within the ice sample. The latter value agrees surprisingly well with the critical shear strength $\tau_{\text {bulk }}=15.7 \mathrm{MPa}$ calculated from Eq. (13) at $-4.5^{\circ} \mathrm{C}, 6 \times 10^{-5} \mathrm{~m} / \mathrm{s}$, and $\delta=10^{-4} \mathrm{~m}$. Then, $k$ is estimated as 0.063 for ice-steel and 0.012 for ice-quartz. But, a comparison of Figs. 6 and 7 suggests that $k$ is also strongly dependent on the sliding velocity.

At present, the estimate of friction coefficients using Eq. (10) at lower temperatures is not possible because we cannot use Eq. (13) at temperatures below $-30{ }^{\circ} \mathrm{C}$. At $-34^{\circ} \mathrm{C}$ and lower temperatures, the measurement by Barnes et al. ${ }^{6}$ was only carried out at strain rates below $10^{-6} \mathrm{~s}^{-1}$, and we have no reliable data of $\tau_{\text {bulk }}$ in an adequate sliding velocity range to calculate friction coefficients. Future measurements of $\tau_{\text {bulk }}$ at lower temperatures are required to calculate the sliding velocity dependence of ice-ice friction at these temperatures.

\section{CONCLUSIONS}

At sliding velocities below $0.01 \mathrm{~m} / \mathrm{s}$, the ice friction is caused by adhesion and shear deformation of ice, and the ice-ice friction coefficient increases with decreasing velocity at $-10{ }^{\circ} \mathrm{C}$ (Fig. 1). The result was in conflict with what has been expected from the traditional adhesion theory developed for the friction of metals. The improved adhesion shear theory takes account of junction growth of ice asperities due to sintering at the sliding interface.

\section{ACKNOWLEDGMENTS}

The authors would like to express their sincere thanks to Messrs. Akira Yasutome of Mayekawa Mfg. Co., Naoki Mizukami of University of Utah, and Shigeki Kanazawa of Seiko Epson Co., who have carried out friction measurements as their Master's theses at the Graduate School of Environmental Earth Science, Hokkaido University. The authors are also indebted to Mr. Gaku Matsumoto for his assistance in data analyses, and Dr. Akira Kouchi, Dr. Yukiko Mizuno, and Dr. Naoki Watanabe of the Institute of Low- 
Temperature Science, Hokkaido University for their interest and discussion on the subject. The work was partly supported by a grant-in-aid for scientific research from the Japan Society for the Promotion of Science.

${ }^{1}$ J. Joly, Scientific Proceedings of the Royal Dublin Society 5, Pt. 6, 453 (1887).

${ }^{2}$ O. Reynolds, Papers on Mathematical and Physical Subjects, B (Cambridge University Press, Cambridge, UK, 1901), p. 737.

${ }^{3}$ F. P. Bowden and T. P. Hughes, Proc. R. Soc. London, Ser. A 172, 280 (1939).

${ }^{4}$ F. P. Bowden and D. Tabor, The Friction and Lubrication of Solids (Oxford University Press, Oxford, 1964), p. 544.

${ }^{5}$ D. C. B. Evans, J. F. Nye, and K. J. Cheeseman, Proc. R. Soc. London, Ser. A 347, 793 (1976).

${ }^{6}$ P. Barnes, D. Tabor, and J. C. F. Walker, Proc. R. Soc. London, Ser. A 324, 127 (1971)

${ }^{7}$ K. Tusima, J. Glaciol. 19, 225 (1977).

${ }^{8}$ P. Oksanen and J. Keinonen, Wear 78, 315 (1982).

${ }^{9}$ A. Yasutome, M. Arakawa, and N. Maeno, Seppyo 61, 437 (1999).

${ }^{10}$ N. Mizukami and N. Maeno, Seppyo 62, 515 (2000).

${ }^{11}$ S. Kanazawa, M. Arakawa, and N. Maeno, Seppyo 65, 389 (2003).

${ }^{12}$ N. Maeno, M. Arakawa, A. Yasutome, N. Mizukami, and S. Kanazawa, Can. J. Phys. 81, 241 (2003).
${ }^{13}$ M. Beeman, W. B. Durham, and S. H. Kirby, J. Geophys. Res. 93, 7625 (1988).

${ }^{14}$ D. E. Jones, M. S. thesis, Thayer School of Engineering, Dartmouth College, Hanover, 1989.

${ }^{15}$ G. Casassa, H. Narita, and N. Maeno, J. Appl. Phys. 69, 3745 (1991).

${ }^{16}$ S. C. Lim and M. F. Ashby, Acta Metall. 35, 1 (1987).

${ }^{17}$ T. F. J. Quinn and W. O. Winer, Wear 102, 67 (1985).

${ }^{18}$ D. Tabor, Proc. R. Soc. London, Ser. A 251, 378 (1959).

${ }^{19}$ W. D. Kingery, J. Appl. Phys. 31, 833 (1960).

${ }^{20}$ D. Kuroiwa, Tellus 13, 252 (1961).

${ }^{21}$ P. B. Hobbs and B. J. Mason, Philos. Mag. 9, 181 (1964).

${ }^{22}$ R. Ramseier and C. M. Keeler, J. Glaciol. 6, 421 (1966).

${ }^{23}$ H. H. G. Jellinek and S. H. Ibrahim, J. Colloid Interface Sci. 25, 245 (1967).

${ }^{24}$ G. C. Kuczynski, J. Metals 1, 169 (1949).

${ }^{25}$ N. Maeno and T. Ebinuma, J. Phys. Chem. 87, 4103 (1983).

${ }^{26}$ Y. Mizuno and G. Wakahama, Low Temperature Science A38, 18 (1979).

${ }^{27}$ S. Jones, J. Glaciol. 28, 171 (1982).

${ }^{28}$ D. M. Cole, J. Glaciol. 33, 274 (1987).

${ }^{29}$ M. Arakawa and N. Maeno, Cold Regions Sci. Tech. 26, 215 (1997).

${ }^{30}$ F. E. Kennedy, E. M. Schulson, and D. E. Jones, Philos. Mag. A 80, 1093 (2000).

${ }^{31}$ E. L. Offenbacher, I. C. Roselman, and D. Tabor, Physics and Chemistry of Ice, edited by E. Whalley et al. (Royal Soc. of Canada, 1973), p. 377.

${ }^{32}$ H. H. G. Jellinek, U.S. Army SIPRE Res. Report, 38, 1 (1957).

${ }^{33}$ H. H. G. Jellinek, U.S. Army SIPRE Res. Report, 62, 1 (1960). 